\title{
Correlation of GNSS Observation Data Quality Resulted from TEQC Checking and Coordinate's Precision
}

\author{
Yulaikhah $^{1,3}$, Subagyo Pramumijoyo ${ }^{2}$, Nurrohmat Widjajanti ${ }^{3}$ \\ 1 Mahasiswa S3 Ilmu Teknik Geomatika Departemen Teknik Geodesi Fakultas Teknik UGM \\ 2 Departemen Teknik Geologi Fakultas Teknik UGM \\ ${ }^{3}$ Departemen Teknik Geodesi Fakultas Teknik UGM
}

\section{Article History:}

Received 29 August 2018

Received in revised form 12 September 2018

Accepted 19 September 2018

Available online 25 September 2018

\section{Keywords:}

korelasi, multipath, teqc, ketelitian

koordinat, ionosfer delay

Corresponding Author:

Yulaikhah

Email: yulaikhah@ugm.ac.id

\begin{abstract}
GPS Positioning provides good coordinate accuracy that is up to a millimeter. However, some error sources such as multipath, atmospheric conditions and obstruction can reduce the quality of data and also coordinates. To minimize errors due to these factors, at the time of determining the station location, it is necessary to pay attention to the surrounding conditions, namely by looking for open areas and avoiding objects that can reflect GNSS signals. However, it is often not easy to find the ideal observation station location, which forms a good chain while being free from obstruction and multipath. Therefore, it is often necessary to prioritize certain factors over other factors. Information about the correlation between multipath, ionospheric conditions and the recording level of observational data on coordinate accuracy can be used as consideration in determining the location of control points for deformation monitoring and determining which factors are prioritized. This study aims to evaluate the correlation between data quality and coordinates precision. The used observation data are Sermo Reservoir control network and nine CORS BIG stations. The component data analyzed are multipath (MP1, MP2), ionospheric effects (IOD slips and IOD or MP slips) and the data recording level (obs). These components were resulted by checking with TEQC software, while the precision of the coordinates was obtained by processing with GAMIT / GLOBK software. Based on the correlation coefficient value, it is known that the recording level of observation data has the strongest correlation with a negative direction (ranging from -0.7 to -0.9). It is the ratio between the number of real observations to the number of possible ones. One factor that influences it is the obstruction in the field. In other words, in determining the location of GNSS observation stations, the conditions of obstruction in the vicinity need to be considered and prioritized.
\end{abstract}

(C) Author(s) 2018. This is an open access article under the Creative Commons Attribution-ShareAlike 4.0 International License (CC BY-SA 4.0).

\section{Pendahuluan}

Global Navigation Satellite Systems (GNSS) yang terdiri atas Global Positioning System (GPS) milik Amerika Serikat, GLONASS milik Rusia, Galileo milik Uni Eropa dan Beidou (juga disebut COMPASS) milik Cina serta beberapa sistem satelit navigasi regional, dapat dikategorikan sebagai metode penentuan posisi dengan tingkat presisi yang tinggi, kontinyu, dalam segala cuaca dan real time. Dengan karakteristik seperti tersebut, aplikasi GNSS untuk penentuan posisi semakin luas dan sangat potensial (Jin dkk. 2014). GNSS, terutama GPS saat ini telah banyak digunakan secara luas untuk keperluan pemantauan deformasi baik deformasi struktur maupun deformasi lainnya seperti longsor, aktifitas gunung berapi, pergerakan lempeng dan sebagainya. Hal ini dikarenakan metode GPS mampu memberikan hasil dengan ketelitian yang baik sampai dengan fraksi milimeter. Namun demikian beberapa sumber kesalahan seperti multipath, kondisi atmosfir serta kondisi obstruksi dapat menurunkan kualitas data 
pengamatan yang pada akhirnya dapat menurunkan ketelitian koordinat yang dihasilkan. Multipath terjadi karena antena GNSS tidak hanya dapat menerima sinyal langsung dari satelit, tetapi juga dari beberapa sinyal tidak langsung karena pantulan sinyal atau difraksi, sehingga sinyal mengalami keterlambatan. Ionosfer adalah salah satu sumber kesalahan penting dalam navigasi GNSS, posisi dan waktu. Ketika sinyal gelombang elektromagnetik GNSS melewati ionosfer, maka sinyal mengalami keterlambatan dan jalur perjalanan akan sedikit berubah. Saat ini delay ionosfer merupakan salah satu sumber kesalahan utama dalam pengukuran GNSS, yang seharusnya dipertimbangkan dengan cermat untuk dapat memperoleh presisi yang lebih tinggi dalam aplikasi GNSS. Selain itu pada saat melewati troposfer sinyal GNSS dibiaskan, sehingga kecepatan sinyal berubah dan sinyal membentuk kurva/melengkung. Kesalahan akibat efek ionosfer dan bias troposfer ini dapat dimodelkan dengan model matematik tertentu.

Untuk meminimalkan kesalahan akibat faktor-faktor tersebut, maka pada saat desain jaringan pemantauan, penentuan lokasi titik kontrol perlu memperhatikan kondisi di sekitarnya yaitu dengan mencari daerah yang terbuka dan menghindari objek-objek yang dapat memantulkan sinyal GNSS. Namun hal tersebut tidaklah mudah, mengingat jaring pemantauan juga perlu didesain agar secara geometri memenuhi kriteria ketelitian, kehandalan dan sensitif terhadap deformasi yang terjadi. Di lapangan seringkali tidak mudah menemukan lokasi yang ideal yaitu yang memenuhi syarat geometri sekaligus bebas dari obyek sumber multipath dan obstruksi sehingga seringkali harus mengorbankan salah satu diantaranya. Faktor manakah yang harus diprioritaskan? Informasi tentang korelasi antara multipath, kondisi ionosfer dan tingkat perekaman data pengamatan terhadap ketelitian koordinat barangkali dapat membantu sebagai bahan pertimbangan dalam penentuan lokasi titik kontrol pemantauan deformasi dan menentukan faktor mana yang lebih diprioritaskan. Oleh karena itu penelitian ini bertujuan untuk mengevaluasi korelasi antara kualitas data yang meliputi komponen multipath (MP1, MP2), efek ionosfer (IOD slips dan IOD or MP slips) dan tingkat perekaman data (obs) hasil pengecekan data pengamatan jaring pemantauan Waduk Sermo dengan perangkat lunak TEQC, terhadap ketelitian koordinat hasil pengolahan dengan perangkat lunak GAMIT/GLOBK.

\section{Data dan Metodologi}

Prinsip dasar dalam sistem navigasi satelit adalah penentuan posisi suatu tempat di bumi didasarkan pada metode reseksi atau trilaterasi, dari suatu tempat di permukaan bumi ke satelit. Jarak ke satelit diperoleh dengan mengukur waktu perjalanan sinyal radio dari receiver ke satelit. Karena perjalanan sinyal radio dengan kecepatan cahaya, maka diperlukan jam yang sangat teliti. Jarak ke satelit dapat dihitung dengan mengalikan waktu perjalanan dengan kecepatan cahaya.
Dalam sistem GPS, posisi receiver dapat ditentukan dari jaraknya terhadap minimum empat satelit, tiga untuk menghitung posisi 3D dan yang keempat untuk sinkronisasi waktu untuk memperbaiki kesalahan jam receiver. Pengukuran bisa dengan pseudorange ataupun beda phase (Lechner W.and Baumann S, 2000). Akurasi hasil pengukuran GPS dipengaruhi oleh beberapa faktor diantaranya adalah multipath dan kondisi atmosfer baik ionosfer maupun troposfer. Multipath terjadi karena antena GNSS tidak hanya dapat menerima sinyal langsung dari satelit, tetapi juga dapat menerima beberapa sinyal tidak langsung karena pantulan sinyal atau difraksi, sehingga sinyal mengalami keterlambatan, sedangkan efek ionosfer terjadi ketika sinyal gelombang elektromagnetik GNSS melewati ionosfer, maka sinyal mengalami keterlambatan dan jalur perjalanan akan sedikit berubah.

\subsection{Data dan Lokasi Penelitian}

Pada penelitian ini digunakan data pengamatan GNSS titik kontrol pada jaring pemantauan deformasi Waduk Sermo dan data RINEX stasiun CORS Badan Informasi Geospasial (BIG). Data pengamatan titik kontrol Waduk Sermo yang digunakan yaitu BMS2, MAK1, MAK2, MAK3, MAK4, dan MAK5. Proses pengamatan dilakukan selama \pm 72 jam dari doy $133 \mathrm{s.d}$ 136 tahun 2016. Pengukuran dilakukan dengan metode diferensial dengan sampling rate 15 detik. Lokasi dan persebaran stasiun pengamatan Waduk Sermo dapat dilihat pada Gambar 2.1. Data pengamatan stasiun CORS BIG yang digunakan yaitu CBTL, CKBM, CMGL, CPBL, CPKL, CPTS, CPWD, CSEM dan CSLO, selama delapan doy tahun 2016, yaitu dari doy 131 s.d 138, kecuali titik CKBM yang hanya tujuh doy yaitu dari doy 132 s.d 138. Lokasi dan persebaran stasiun CORS BIG dapat dilihat pada Gambar 2.2.

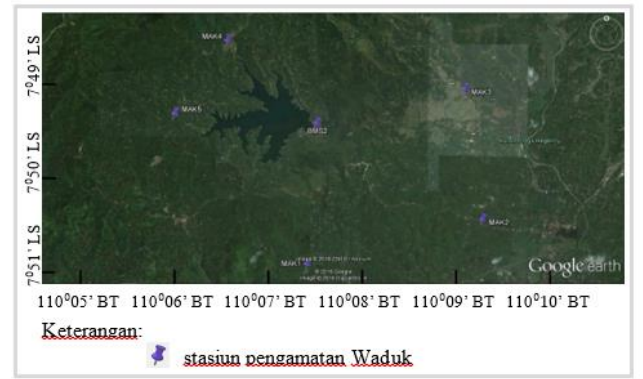

Gambar 2.1 Distribusi titik kontrol pemantauan deformasi Waduk Sermo

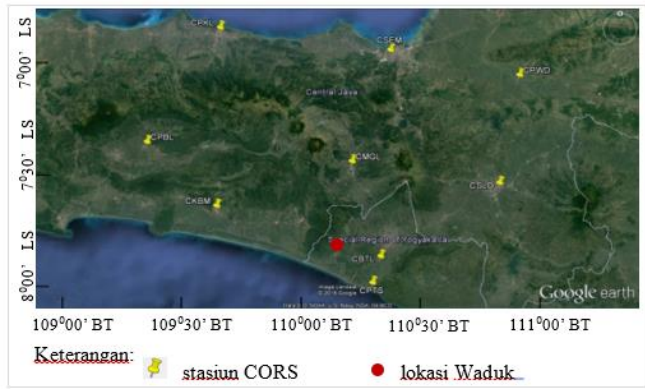

Gambar 2.2 Distribusi stasiun CORS BIG 
Sebelum dilakukan pengolahan, data pengamatan GNSS jaring kontrol pemantauan deformasi Waduk Sermo dan CORS BIG dievaluasi dengan perangkat lunak TEQC. Adapun komponen yang dievaluasi hanya pada informasi terkait multipath (MP1, MP2), efek ionosfer (IOD slips dan IOD or MP slips) dan tingkat perekaman data $(o b s)$. Selanjutnya pengolahan data pengamatan GNSS dilakukan dengan perangkat lunak ilmiah GAMIT/GLOBK. Hasil keluaran dari proses pengolahan ini berupa koordinat titik-titik kontrol beserta simpangan bakunya. Korelasi antara multipath dan ionosfer terhadap ketelitian koordinat dilakukan dengan menghitung nilai korelasi antara data multipath dan efek ionosfer hasil dari perangkat lunak TEQC dengan data simpangan baku koordinat titik kontrol hasil pengolahan dengan perangkat lunak GAMIT/GLOBK.

\subsection{Evaluasi Kualitas Data Pengamatan}

Untuk mengevaluasi kualitas data pengamatan GNSS sebelum pengolahan, dilakukan dengan perangkat lunak/program tak berbayar yang disebut dengan Translation, Editing, Quality Checking (TEQC). Sesuai dengan namanya, program ini memiliki tiga fungsi utama yaitu mengkonversi dari format asli biner ke format standar Receiver Independent Exchange (RINEX), mengedit file RINEX, dan pengecekan kualitas data sebelum postprocessing (Estey, L.H. dan Meertens, C.M., 1999). Secara lebih detil program ini dapat digunakan untuk (Estey, L. dan Wier, S., 2014):

a. mengkonversi data pengamatan berformat asli biner tertentu (misalnya, Trimble ${ }^{*}$.dat) ke format RINEX

b. mengecek file atau file RINEX untuk memenuhi spesifikasi RINEX versi 2; sebagai contoh, field header yang harusnya muncul namun tidak ada, dapat diidentifikasi

c. memodifikasi dan menyunting field header RINEX yang ada di file

d. memeriksa kualitas file RINEX yang valid,

e. memotong jendela pengamatan, atau memotong data pengamatan menjadi dua atau lebih file RINEX.

f. membuat file RINEX baru dengan interval sampel yang lebih panjang, misalnya dari 1 detik sampai 30 detik.

Algoritma dasar yang digunakan dalam TEQC untuk cek kualitas mengikuti persamaan yang sama dengan yang digunakan dalam program QC UNAVCO. Pengukuran fase dan pseudorange dimodelkan sebagai berikut (Hatch, 1982; Kelecy, 1990; Rocken dkk., 1996 dalam Estey, L.H. dan Meertens, C.M., 1999):

$$
\begin{gathered}
L_{i}=R+c\left(d t_{r}+d t_{s}\right)-I_{i}+N+m_{i}+n_{i} \lambda_{i} \\
P_{i}=R+c\left(d t_{r}+d t_{s}\right)+I_{i}+N+M_{i}
\end{gathered}
$$

Dalam hal ini :

$\mathrm{Li}_{\mathrm{i}} \quad$ : data fase yang dapat diamati untuk frekuensi i (yaitu, RINEX LI atau L2)

$\mathrm{P}_{\mathrm{i}} \quad$ : data pseudorange yang dapat diamati untuk frekuensi i (yaitu, RINEX P1 atau P2)

$\mathrm{R} \quad$ : jarak antara satelit dan antena

c : kecepatan cahaya

dtr : kesalahan jam receiver

dts : kesalahan jam satelit

$\mathrm{I}_{\mathrm{i}} \quad$ : kesalahan ionosfer untuk frekuensi i

$\mathrm{N}$ : penundaan atmosfer netral

$\mathrm{m}_{\mathrm{i}} \quad$ : multipath fase untuk frekuensi i

$\mathrm{M}_{\mathrm{i}} \quad$ : multipath pseudorange untuk frekuensi i

$n_{i} \lambda_{i} \quad$ : ambiguitas fase panjang gelombang integer untuk frekuensi i

Pengecekan file data pengamatan dalam format RINEX yang digunakan sebagai input dalam pengolahan dilakukan dengan perangkat lunak TEQC metode $q c$-full, dimana proses pengecekan melibatkan file observasi yang berekstensi *.yyo serta file navigasi (GPS) yang berekstensi *.yyn. Hal ini agar diperoleh informasi yang lengkap mengenai kondisi dan kualitas data. Selain itu dengan menggunakan metode $q c$-full, TEQC dapat memperoleh informasi mengenai posisi satelit yang terekam pada data pengamatan. Dalam melakukan pengecekan data menggunakan TEQC, ada beberapa parameter yang harus terpenuhi agar data dapat dikualifikasikan baik (Lestari, 2006), diantaranya adalah:

1. Nilai MP1 dan MP2 kurang dari 0,5 m.

2. Nilai IOD slips kurang dari 100.

3. Nilai IOD or MP slips kurang dari 100.

4. Tingkat perekaman data, semakin mendekati $100 \%$ semakin baik

Nilai MP1 dan MP2 merupakan multipath yang merupakan kombinasi linear antara pengamatan pseudorange dan carrier phase, yang menunjukkan multipath pseudorange L1 untuk pengamatan kode C/A atau $\mathrm{P}$, dan multipath pseudorange L2 untuk pengamatan kode $P$. Nilai ini menunjukkan rata-rata (RMS) multipath MP1 dan MP2 dalam meter. Pada mode qc-full nilai MP1 dan MP2 adalah saat pengamatan berada di atas elevation mask. Dalam TEQC, MP1 dan MP2 dimodelkan dengan persamaan berikut (Estey, L.H. dan Meertens, C.M., 1999):

$$
\begin{aligned}
M P 1 & =P_{1}-\left(1+\frac{2}{\alpha-1}\right) L_{1}+\left(\frac{2}{\alpha-1}\right) L_{2} \\
& =M_{1}+B_{1}-\left(1+\frac{2}{\alpha-1}\right) m_{1}+\left(\frac{2}{\alpha-1}\right) m_{2}
\end{aligned}
$$

$$
\begin{aligned}
M P 2 & =P_{2}-\left(\frac{2 \alpha}{\alpha-1}\right) L_{1}+\left(\frac{2 \alpha}{\alpha-1}-1\right) L_{2} \\
& =M_{2}+B_{2}-\left(\frac{2 \alpha}{\alpha-1}\right) m_{1}+\left(\frac{2 \alpha}{\alpha-1}-1\right) m_{2}
\end{aligned}
$$

Sementara itu, IOD slips, IOD or MP slips adalah efek dari kondisi atmosfer terutama pada lapisan ionosfer 
yang mempengaruhi kecepatan sinyal GPS dari satelit ke receiver, pada TEQC dimodelkan dengan persamaan (5):

$$
I_{(2)} O D=\frac{\alpha}{\alpha-1}\left[\left(L_{1}-L_{2}\right)_{j}-\left(L_{1}-L_{2}\right)_{j-1}\right] /\left(t_{j}-t_{j-1}\right)(5)
$$

Tingkat perekaman data dapat dilihat pada nilai persentase pengamatan (\%). Nilai \% ini merupakan perbandingan antara jumlah perekaman data riil (complete observation) terhadap jumlah perekaman

\subsection{Pengolahan Data Pengamatan GNSS dengan GAMIT/GLOBK}

GAMIT/GLOBK merupakan perangkat lunak komprehensif untuk analisis data GPS yang dikembangkan oleh MIT, Harvard-Simthsonian Center for Astrophysics (CfA) Scripps Institution of Oceanography (SIO) dan Australian National University. Perangkat ini berfungsi untuk mengestimasi koordinat dan kecepatan stasiun, representasi fungsional dan stokastik dari post-seismic deformation, delay atmosfer, orbit satelit dan parameter orientasi bumi. GAMIT mulanya dikembangkan pada tahun 1960-an oleh Lincoln Laboratory sebelum disempurnakan pada tahun1980-an oleh MIT, dan telah mengalami pengembangan sampai seperti saat ini dengan kontribusi dari beberapa institusi yang terlibat didalamnya. Untuk mengontrol pengolahan, perangkat lunak tersebut menggunakan skrip C-shell yang digunakan untuk memanggil program Fortran atau C yang disusun dalam direktori /libraries, /gamit, dan /kf. GLOBK dikembangkan oleh Herring di CfA untuk kombinasi data VLBI dan kemudian dimodifikasi oleh MIT untuk menggabungkan data GPS. GLOBK adalah filter Kalman yang tujuan utamanya adalah untuk menggabungkan solusi dari pengolahan data survei ekstra-terestris dan terestris. Data input pada GLOBK adalah matriks varian kovarian dari data koordinat data yang mungkin (possible observation) saat pengamatan berada di atas elevation mask, yang dinyatakan dalam persen. Parameter-parameter tersebut yang selanjutnya digunakan untuk menganalisa file observasi RINEX sebelum dilakukan pengolahan.

Parameter-parameter tersebut dapat dilihat pada ringkasan laporan keluaran program TEQC, seperti pada contoh berikut :

$\begin{array}{lllrrrr}\text { dt } & \text { \#expt } & \text { \#have } & 8 & m p 1 & m p 2 & \text { o/slps } \\ 30 & 41538 & 41293 & 99 & 0.39 & 0.49 & 41293\end{array}$

stasiun, parameter rotasi bumi, parameter orbit, dan koordinat hasil pengamatan berupa h-file (Herring T.A., 2017a).

Pengolahan data pengamatan GNSS pada penelitian ini menggunakan perangkat lunak GAMIT/GLOBK. Pengolahan terbagi menjadi tiga skema seperti pada Tabel 1. Adapun prosedur pengolahannya secara lengkap dapat dilihat di (Herring T.A., 2017b, Herring T.A., 2017c). Pada skema 1 data pengamatan titik kontrol Waduk Sermo diolah menggunakan titik ikat global IGS. Skema 2 mengolah data pengamatan stasiun CORS BIG menggunakan titik ikat global IGS. Skema 3 mengolah data pengamatan titik kontrol Waduk Sermo menggunakan stasiun CORS BIG sebagai titik ikat. Hasil keluaran dari proses pengolahan ini berupa koordinat beserta simpangan bakunya.

Tabel 2.1 Skema Pengolahan Data Pengamatan GNSS dengan Perangkat Lunak GAMIT/GLOBK (Sumber : Rakhmatullah, 2017)

\begin{tabular}{|c|c|c|c|}
\hline \multirow{3}{*}{ SKEMA } & $\begin{array}{c}\text { STASIUN } \\
\text { YANG } \\
\text { DIOLAH }\end{array}$ & TITIK IKAT & DOY \\
\hline \multirow{5}{*}{ Skema1 } & BMS2, & & \\
& MAK1, & ALIC, BAKO, DARW, & 133 \\
& MAK2, & DGAV, GUAM, HYDE, & 13 \\
& MAK3, & KARR, PIMO, TCMS, & 136 \\
& MAK4, & TOW2 & \\
\hline \multirow{5}{*}{ Skema2 } & MAK5 & & \\
& CBTL, & & \\
& CKBM, & ALIC, BAKO, DARW, & 131 \\
& CMGL, & DGAV, GUAM, HYDE, & s.d \\
& CPBL, & KARR, PIMO, TCMS, & 138 \\
& CPL, CPTS, & TOW2 & \\
& CPWD, & & \\
\hline \multirow{5}{*}{ CSEM, CSLO } & & \\
& BMS2, & & \\
& MAK1, & CBTL, CKBM, CMGL, & 133 \\
& MAK2, & CPBL, CPKL, CPTS, & s.d \\
& MAK3, & CPWD, CSEM, CSLO & 136 \\
& MAK4, & & \\
\hline & MAK5 & & \\
\hline
\end{tabular}




\subsection{Perhitungan Korelasi}

Nilai korelasi dikenal sebagai koefisien korelasi antara dua variabel, menunjukkan kedekatan hubungan diantara keduanya yaitu hubungan linier antara kedua variabel. Nilai korelasi (r) dari -1 s.d. +1 dan tidak mempunyai satuan. Jika nilainya negatif bersifat berlawaan arah. Nilai korelasi dapat dihitung dengan persamaan (6) berikut (Supranto J., 2000) :

$$
r=\frac{\sum\left(\bar{x}-x_{i}\right)\left(\bar{y}-y_{i}\right)}{\sqrt{\Sigma}\left(\bar{x}-x_{i}\right)^{2} \cdot \sqrt{\Sigma}\left(\bar{y}-y_{i}\right)^{2}}
$$

Perhitungan nilai korelasi pada penelitian ini dilakukan antara nilai MP1, MP2, IOD slips, IOD or MP Slips dan tingkat perekaman data pada masing-masing skema pengolahan terhadap nilai simpangan baku koordinat yang dihasilkan.

\section{Hasil dan Pembahasan}

Seperti disampaikan bahwa multipath, kondisi atmosfer dan obstruksi di lapangan termasuk sebagai faktor yang dapat menurunkan ketelitian hasil pengukuran GNSS. Pada saat desain jaringan, seringkali dihadapkan pada kondisi lapangan yang sulit, dimana kondisi sumber multipath dan obstruksi sangat bervariasi, sehingga tidak mudah untuk menentukan lokasi titik yang ideal yaitu bebas obstruksi dan multipath. Jika dihadapkan pada pilihan faktor mana yang perlu lebih diperhatikan, maka hasil perhitungan korelasi antara faktor-faktor tersebut terhadap ketelitian koordinat berikut ini dapat dijadikan sebagai salah satu bahan pertimbangan.

Nilai korelasi antara kualitas data pengamatan jaring kontrol pemantauan deformasi Waduk Sermo (SKEMA1 dan SKEMA3) dapat dilihat pada Gambar 3.1 dan 3.2. Yang membedakan antara SKEMA1 dan SKEMA3 adalah titik ikat yang digunakan, SKEMA1 menggunakan titik ikat global IGS, sedangkan SKEMA3 menggunakan titik ikat CORS BIG. Hal ini berkaitan dengan kondisi atmosfer. Pada SKEMA1 kondisi atmosfer dimungkinkan relatif berbeda antara stasiun IGS dengan titik kontrol pemantauan deformasi Waduk Sermo karena jarak yang sangat jauh, sedangkan pada SKEMA3 kondisi atmosfer dimungkinkan relatif sama. Meskipun demikian, ketelitian koordinat yang dihasilkan kedua skema tersebut hampir sama.

Berdasarkan Gambar 3.1 dan 3.2, koefisien korelasi pada SKEMA1 dan SKEMA3 memiliki pola yang sama. Efek multipath dan kondisi atmosfer memiliki korelasi positif yaitu berturut-turut berkisar 0,4-0,6 dan 0,6-0,8. Hal ini berarti semakin besar nilai MP1, MP2, IOD Slips dan IOD or MP Slips maka semakin menurunkan ketelitian koordinat dan efek atmosfer memiliki korelasi yang lebih kuat dibandingkan multipath. Sebaliknya, tingkat perekaman data pengamatan memiliki korelasi yang negatif, artinya semakin tinggi tingkat perekaman data, ketelitian koordinat semakin baik. Terlihat bahwa tingkat perekaman data pengamatan memiliki korelasi paling kuat yaitu berkisar -0,7 sampai dengan -0,9. Tingkat perekaman data pengamatan merupakan rasio antara jumlah pengamatan yang terekam terhadap jumlah pengamatan yang mungkin. Salah satu faktor yang mempengaruhi tingkat perekaman data pengamatan adalah obstruksi yang ada di lapangan. Oleh karena itu dapat dikatakan bahwa pada penentuan lokasi titik pengamatan GNSS kondisi obstruksi di sekitarnya perlu lebih diperhatikan dan diprioritaskan. Meskipun demikian, tidak menutup kemungkinan delay akibat ionosfer atau multipath juga dapat mempengaruhi (menurunkan) tingkat perekaman data.

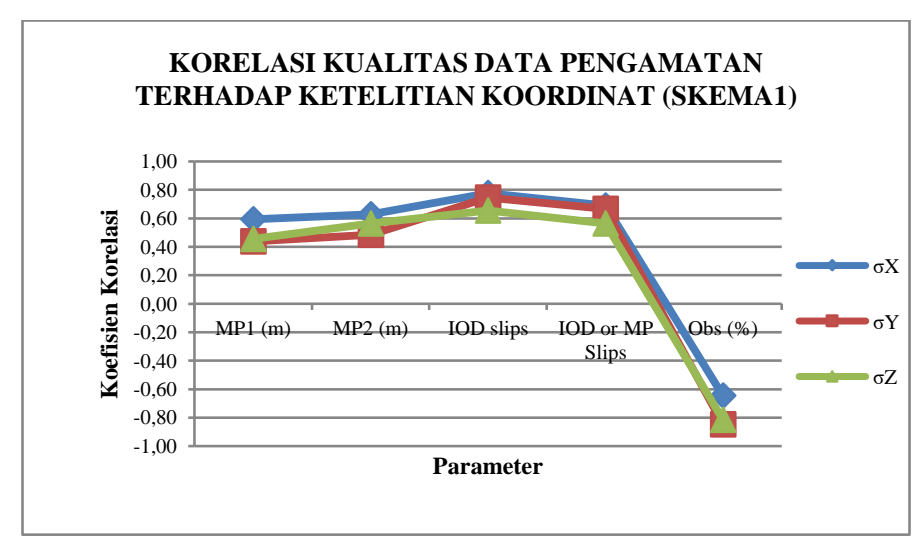

Gambar 3.1 Koefisien Korelasi pada SKEMA1

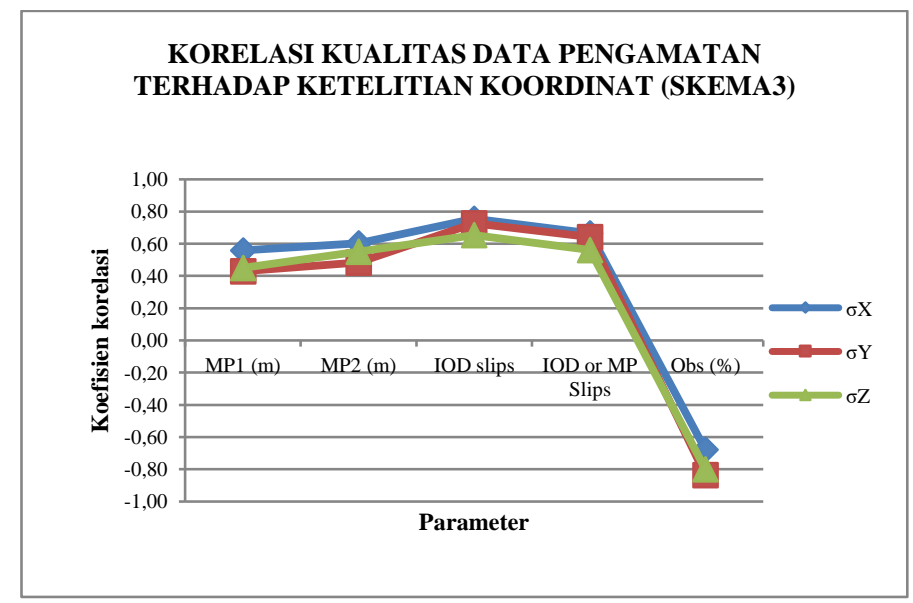

Gambar 3.2 Koefisien Korelasi pada SKEMA3

Secara umum, pola korelasi yang sama terjadi pada data pengamatan CORS BIG (SKEMA2) seperti terlihat pada Gambar 3.3. Hal yang menarik adalah berbeda dengan SKEMA 1 dan SKEMA3, pada skema ini tingkat perekaman data pengamatan justru memiliki koefisien korelasi yang rendah, lebih rendah dibandingkan korelasi efek ionosfer. Hal ini dimungkinkan karena data tingkat perekaman pengamatan di stasiun-stasiun CORS BIG relatif homogen dan bagus yaitu berkisar 
95\%-100\%. Hanya stasiun CSLO yang memiliki tingkat perekaman $86 \%$. Hal ini sangat realistis, mengingat stasiun CORS BIG beroperasi secara kontinyu dan dipersiapkan untuk jangka waktu yang lama, sehingga variasi ketelitian koordinat lebih dipengaruhi oleh faktor lainnya.

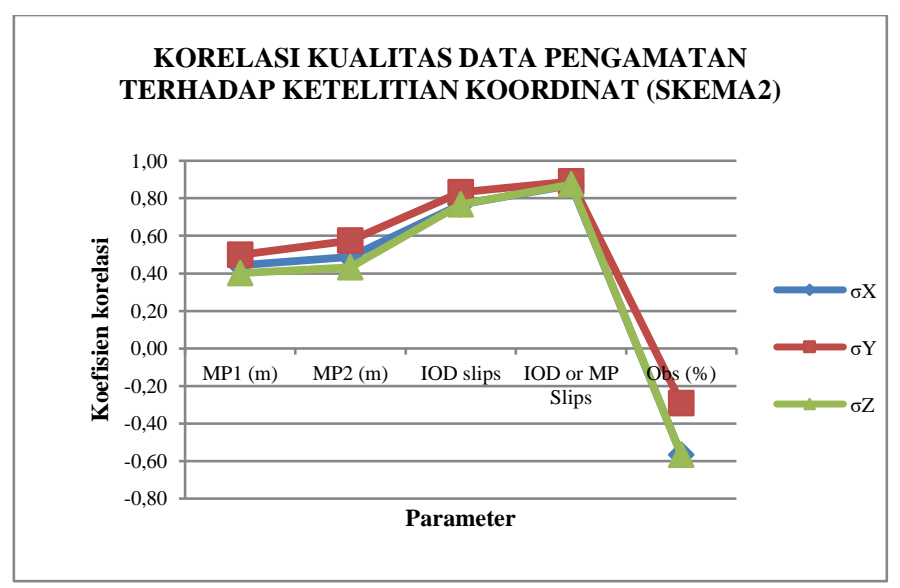

Gambar 3.3 Koefisien Korelasi pada SKEMA2

Seperti halnya pada SKEMA1 dan SKEMA3, korelasi efek atmosfer lebih kuat dibandingkan dengan efek multipath. Oleh karena itu efek atmosfer juga perlu diperhatikan. Efek atmosfer ini bisa dimodelkan menggunakan fungsi matematik tertentu dan diterapkan pada saat pengolahan data pengamatan GNSS. Berdasarkan hasil ketiga skema tersebut, efek multipath memiliki nilai koefisien korelasi paling rendah.

\section{Kesimpulan}

Diantara ketiga parameter kualitas data pengamatan GNSS, efek multipath, efek atmosfer dan tingkat perekaman data, parameter tingkat perekaman data memiliki korelasi paling kuat terhadap ketelitian koordinat dan bertanda negatif yaitu dengan koefisien korelasi berkisar $-0,7$ sampai dengan $-0,9$. Tingkat perekaman data pengamatan merupakan rasio antara jumlah data pengamatan yang terekam terhadap jumlah pengamatan yang mungkin. Salah satu faktor yang mempengaruhi tingkat perekaman data pengamatan adalah kondisi obstruksi di lapangan. Oleh karena itu pada penentuan lokasi titik pengamatan GNSS kondisi obstruksi di sekitarnya perlu lebih diperhatikan dan diprioritaskan. Meskipun demikian, tidak menutup kemungkinan delay akibat ionosfer atau multipath juga dapat mempengaruhi (menurunkan) tingkat perekaman data. Efek atmosfer memiliki korelasi yang lebih kuat dibandingkan multipath, oleh karena itu perlu menerapkan model matematik tertentu pada proses pengolahan data pengamatan GNSS. Untuk mendapatkan hasil yang lebih akurat, perlu dilakukan analisis korelasi menggunakan jumlah stasiun pengamatan yang lebih banyak.

\section{Pernyataan Konflik Kepentingan}

Penulis menyatakan tidak ada konflik kepentingan dalam artikel ini (The authors declare no competing interest).

\section{Referensi}

Estey, L., Wier, S. (2014). Teqc Tutorial: Basic of TEQC Use and Teqc Products, UNAVCO Inc., Colorado U.S.A.

Estey, L.H. dan Meertens, C.M. (1999). TEQC: The MultiPurpose Toolkit for GPS/GLONASS Data. GPS Solutions, Vol. 3, No. 1, pp. 42-49 (C) 1999 John Wiley \& Sons, Inc.

Herring, T.A., King, R.W., Floyd M.A., dan McClusky, S.C. (2015a). Introduction to GAMIT/GLOBK Departmen of Earth, Atmospheric, and Planetary Science, Massachussets Institute of Technology.

Herring, T.A., King, R.W., Floyd M.A., dan McClusky, S.C. (2015b). GAMIT Reference Manual, GPS Analysis at MIT, Departmen of Earth, Atmospheric, and Planetary Science, Massachussets Institute of Technology.

Herring, T.A., King, R.W., Floyd M.A., dan McClusky, S.C. (2015c)., G L O B K Reference Manual, Global Kalman filter VLBI and GPS analysis program, Departmen of Earth, Atmospheric, and Planetary Science, Massachussets Institute of Technology.

In S., Chardellach E., dan Xie F. (2014). GNSS Remote Sensing Theory, Methods and Applications. Springer. ISBN 978-94-007-7482-7 (eBook).

Lechner W. dan Baumann S. (2000). Global Navigation Satellite System. Computers and Electronics in Agriculture 25 (2000) 67-85, Elsevier.

Lestari, D. (2006). GPS Study Resolving the Stability of Borobudur Temple Site. Thesis School of Surveying and Spatial Information System. Universty of New South Wales.

Rakhmatullah, I. (2017). Evaluasi Ketelitian Koordinat Jaring Kontrol Pemantauan Deformasi Waduk Sermo dengan Pengikatan pada Stasiun CORS BIG dan Stasiun IGS. Skripsi Departemen Teknik Geodesi Fakultas Teknik Universitas Gadjah Mada. Yogyakarta

Supranto, J. (2000). Statistik Teori dan Aplikasi, Edisi 6, Cetakan 1. Erlangga. Jakarta. 